OPEN ACCESS

Edited by:

Zhi-Cong Dai,

Jiangsu University, China

Reviewed by:

Aiping Wu,

Hunan Agricultural University, China

Yong-Jian Wang,

Huazhong Agricultural

University, China

*Correspondence:

Fengjuan Zhang

fengjuanzhang@126.com

Haiyun Xu

xuhaiyun520@sina.com

Specialty section:

This article was submitted to

Population and Evolutionary

Dynamics,

a section of the journa

Frontiers in Ecology and Evolution

Received: 03 November 2020

Accepted: 08 February 2021

Published: 29 March 2021

Citation:

Chen X, Li Q, Wang L, Meng Y, Jiao S,

Yin J, Xu H and Zhang F (2021)

Nitrogen Uptake, Not Transfer of

Carbon and Nitrogen by CMN,

Explains the Effect of AMF on the

Competitive Interactions Between

Flaveria bidentis and Native Species.

Front. Ecol. Evol. 9:625519

doi: 10.3389/fevo.2021.625519

\section{Nitrogen Uptake, Not Transfer of Carbon and Nitrogen by CMN, Explains the Effect of AMF on the Competitive Interactions Between Flaveria bidentis and Native Species}

\author{
Xue Chen ${ }^{1}$, Qiao $\mathrm{Li}^{2}$, Liting Wang ${ }^{1}$, Yanliang Meng ${ }^{1}$, Shaona Jiao ${ }^{1}$, Jilin Yin ${ }^{1}$, Haiyun $\mathrm{Xu}^{1 *}$ \\ and Fengjuan Zhang ${ }^{1 *}$
}

${ }^{1}$ College of Life Science, Hebei University, Baoding, China, ${ }^{2}$ State Key Laboratory for Biology of Plant Diseases and Insect Pests, Institute of Plant Protection Chinese Academy of Agricultural Sciences, Beijing, China

Rhizophagus intraradices, one of the common arbuscular mycorrhizal fungi (AMF) grown in the roots of Flaveria bidentis, facilitates the invasion of this exotic plant species into China. However, it is still unknown whether nutrient transfer through the common mycorrhizal networks (CMN) between this exotic species and the native species enhances the competitive growth of F. bidentis over the native species. To elucidate this question and the related mechanism, an isotopic labeling technique was used to test the transfer of carbon $(\mathrm{C})$ and nitrogen $(\mathrm{N})$ by $\mathrm{CMN}$. Native species like Setaria viridis and Eclipta prostrata were selected to compete with F. bidentis in a polyvinyl chloride (PVC) box. Two competitive groups (F. bidentis-S. viridis and F. bidentis- E. prostrata), three treatments (monoculture of $F$. bidentis, the mixture of $F$. bidentis and the native plant, and the monoculture of the native plant), and two levels of AMF (presence or absence) were assigned. Results showed that the corrected index of relative competition intensity $(\mathrm{CRCl})$ of $F$. bidentis in the presence of $\mathrm{AMF}<0$ suggests that the competition facilitated the growth of $F$. bidentis with either $S$. viridis or E. prostrata. The reason was that the inoculation of $R$. intra radices significantly increased the $C$ and $N$ contents of $F$. bidentis in the mixtures. However, the effects of $R$. intra radices on the two native species were different: negative effect on the growth of $S$. viridis and positive effect on the growth of $E$. prostrata. The change of $\mathrm{N}$ content in $S$. viridis or $E$. prostrata was consistent with the variation of the biomass, suggesting that the $N$ uptake explains the effects of $R$. intraradices on the competitive interactions between $F$. bidentis and the two native species. Moreover, the transfer of $\mathrm{C}$ and $\mathrm{N}$ via AMF hyphal links did occur between $F$. bidentis and the native species. However, the transfer of $\mathrm{C}$ and $\mathrm{N}$ by the $\mathrm{CMN}$ was not positively related to the competitive growth of $F$. bidentis.

Keywords: arbuscular mycorrhizal fungi, exotic species, relative competition intensity, nitrogen acquisition, carbon and nitrogen transfer 


\section{INTRODUCTION}

Arbuscular mycorrhizal fungi (AMF), an ecologically and economically important fungal guild, usually establish mutualistic associations with the majority of exotic plants (Bunn et al., 2015). Increasing evidence suggested that mycorrhizal symbiosis with AMF mediates the competitiveness, diversity, and community structure of the plant species (Lin et al., 2015; Bennett et al., 2017; Teste et al., 2017), thereby contributing to the success of plant invasion (Gerz et al., 2018). For example, some studies indicated that AMF colonization of the exotic species was usually higher than that of the native species. The AMF provided more nutrients to the exotic plants and promoted the competitive ability of the exotic plants relative to the native plants (Yang et al., 2015; Zhang et al., 2017, 2018). Also, other studies showed that the symbiotic relationship between the native plants and the AMF could be changed by the invasion of the exotic species (Callaway et al., 2008; Lekberg et al., 2013; Bunn et al., 2015). The changes in the mutualistic associations might lead to an increase (i.e., positive feedback) in the relative growth rate of the exotic species and a decrease (i.e., negative feedback) in the relative growth rate of the native species (Bever, 2002; Stinson et al., 2006; Pringle et al., 2009).

Arbuscular mycorrhizal fungi usually form extensive common mycorrhizal networks (CMNs), which interconnect the neighboring root systems of the same or different plant species (Weremijewicz et al., 2018). Nutrient acquisition by AMF may come from soil via fungal hyphae or from plants that were connected by CMNs (Yang et al., 2014; Zhang et al., 2017). Recently, a growing body of theory and empirical evidence suggest that nutrient transfer through CMNs between the connected plants, rather than through nutrient acquisition, is relevant to plant growth (Selosse et al., 2006; Bücking et al., 2016). Bücking et al. (2007) and Selosse et al. (2016) argued that CMNs were not only passive conduits for the movement of carbon (C) (Carey and Callaway, 2004) and nutrients (He et al., 2003; Von Thun, 2013), but they might also provide sophisticated fungal-host resource exchange (Song et al., 2010; Babikova et al., 2013), including allelopathic chemicals (Barto et al., 2011) and defense signals (Lekberg et al., 2010; Weremijewicz et al., 2016). Moreover, AMF in CMNs preferentially provide mineral nutrients to those conspecific host individuals that are able to provide them with fixed $\mathrm{C}$ or represent the strongest sinks, thereby potentially amplifying the competition by preferentially allocating mineral nutrients to large host plants (Weremijewicz et al., 2016). Indeed, CMNs had caused size inequality between the networked plants (Fitter et al., 1999; Kiers et al., 2011; Lekberg et al., 2013; Weremijewicz and Janos, 2013). Therefore, some ecologists are of the view that the exotic species outcompeted the native ones as CMNs might have the ability to transfer more $\mathrm{C}$ from the native species to the invasive species (Carey and Callaway, 2004). However, others argued that CMNs had little effect on the competitive interactions among the plant species (Milkereit et al., 2018). Based on the above argument, further studies are still necessary to explore the role of CMNs on the competition between the exotic plants and the native plants.
Flaveria bidentis (L.) Kuntze (Asteraceae), an invader from South America, is one of the most problematic exotic plant species of the family Asteraceae in China (Chen et al., 2004). It typically caused changes in the composition of the plant species and in the biodiversity and community structure of the natural ecosystem (Chen et al., 2004; Ren et al., 2008). F. bidentis can establish symbiotic relationships with AMF (Ji et al., 2015). Rhizophagus intraradices was one of the dominant AMF on the roots and in the rhizosphere soil of $F$. bidentis. The relative abundance of $R$. intraradices was over $15 \%$ both in the roots and in its rhizosphere soil (Zhang et al., 2015b, 2017). Our previous study showed that $R$. intraradices facilitated the competitive growth of $F$. bidentis by promoting the nutrient levels in the leaves of F. bidentis (Zhang et al., 2017). However, it is still unknown whether the increased nutrient was absorbed from the soil or from the CMNs that are connected with the native species. We hypothesized that $R$. intraradices facilitated the competitive growth of $F$. bidentis by transferring $\mathrm{C}$ and nitrogen $(\mathrm{N})$ via CMNs from the native plant species to the invasive species. We tested our hypothesis by studying the effects of colonization (or inoculation) of $R$. intraradices on the growth of $F$. bidentis and of two native plant species, as well as the transfer of $\mathrm{C}$ and $\mathrm{N}$ via CMNs.

\section{MATERIALS AND METHODS}

\section{A Study on Plant Species and $\boldsymbol{R}$. intraradices Inoculum}

Setaria viridis (L.) Beauv. and Eclipta prostrata L. were selected as the native plants. S. viridis and E. prostrata are the typical native weeds of farmlands, pasturelands, and wastelands in China. They are also the dominant plant species in the F. bidentis-invaded habitat in China. S. viridis belongs to the family Poaceae. E. prostrata belongs to the family Asteraceae. The seeds of F. bidentis and the two native species were collected from the Langfang Experimental Station of the Chinese Academy of Agricultural Science (CAAS), China. Seeds were surface-sterilized in $10 \%$ $\mathrm{H}_{2} \mathrm{O}_{2}$ and rinsed five times with sterile distilled water before sowing. The $R$. intraradices inoculum was a mixture of spores and mycelium, which was provided by Professor Liu Runjin from Qingdao Agricultural University.

\section{The Design of the Rhizobox}

Polyvinyl chloride (PVC) boxes were used to test the effect of $R$. intraradices on the competition between $F$. bidentis and the two native plants. The thickness of the PVC boxes was $0.6 \mathrm{~cm}$. Each box was divided into three compartments as shown in Figure 1A and Supplementary Figure 1. Plants were grown in compartments $\mathrm{A}$ and $\mathrm{C}$, respectively. Compartment $\mathrm{B}$ was set up to minimize the risk of free transfer of $\mathrm{C}$ and $\mathrm{N}$ between the compartments $\mathrm{A}$ and $\mathrm{C}$. The size of each of the three compartments measured $20 \times 20 \mathrm{~cm}$ (length $\times$ height), the width of compartments $\mathrm{A}$ and $\mathrm{C}$ were of $25 \mathrm{~cm}$ and that of compartment B was of $10 \mathrm{~cm}$. Compartments $\mathrm{A}$ and $\mathrm{C}$ were separated from compartment B by a nylon mesh (pore size of $30 \mu \mathrm{m}$ ). The nylon mesh prevents the penetration of roots but allows the penetration of hyphae. The three compartments were 
A

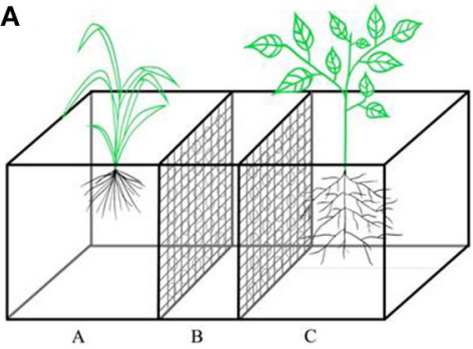

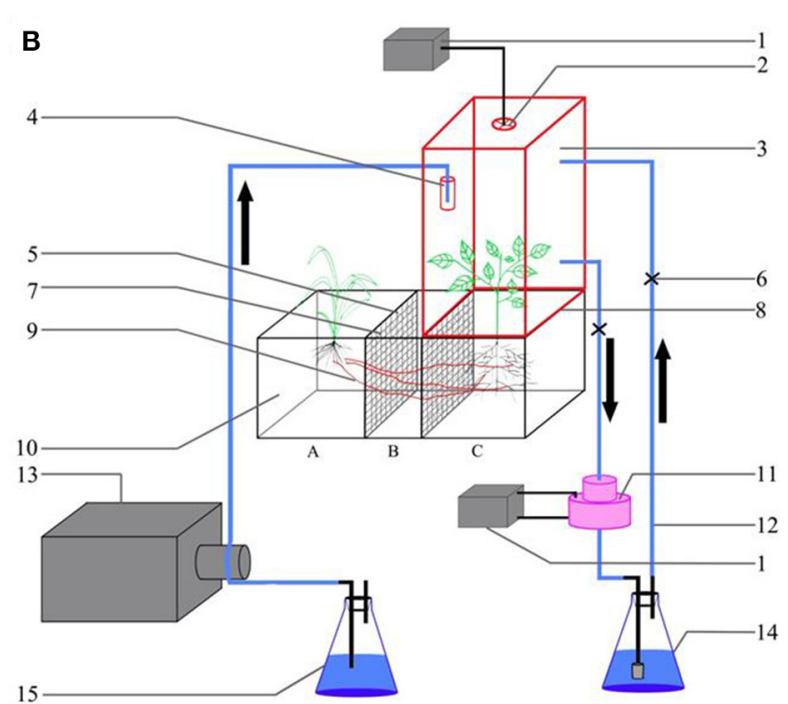

FIGURE 1 | Schematic diagram of three compartment PVC box (A) and ${ }^{13} \mathrm{C}$ labeling (B). 1. Battery; 2. Electric Fan; 3. Sealed container; 4 . Na ${ }_{2}^{13} \mathrm{CO}{ }_{3} ; 5 . \mathrm{Nylon}$ nets $(\varphi$ $=30 \mu \mathrm{m}) ; 6$. Clamp; 7. Hole; 8. Liquid seal rough; 9. Hyphae; 10. Three compartments PVC boxes; 11. Pump; 12. Latex tube; 13. Peristaltic pump; 14. NaOH solution (0.4 mol/L); $15 . \mathrm{H}_{2} \mathrm{SO}_{4}$ solution $(0.36 \mathrm{~mol} / \mathrm{L})$.

filled with a growth substrate (vermiculite: sand: field soil = 1:1:1). The vermiculite $\left[(\mathrm{Mg}, \mathrm{Fe}, \mathrm{Al})_{3}\left[(\mathrm{Si}, \mathrm{Al})_{4} \mathrm{O}_{10}(\mathrm{OH})_{2}\right] .4 \mathrm{H}_{2} \mathrm{O}\right]$ and sand were purchased from Niuniu Plant and Flower Co., Ltd., Langfang, China. The soil was collected from a field, at the Langfang Experimental Station of CAAS, without the history of $F$. bidentis invasion. The chemical properties of the soil were measured (Olsen, 1954; Whitehead et al., 1981) as follows: organic matter, $15.4 \mathrm{~g} \mathrm{~kg}^{-1}$; available $\mathrm{N}, 56.1 \mathrm{~g} \mathrm{~kg}^{-1}$; available potassium, $214.6 \mathrm{~g} \mathrm{~kg}^{-1}$; and available phosphorus, $9.9 \mathrm{~g} \mathrm{~kg}^{-1}$. The growth substrate was sterilized at $121^{\circ} \mathrm{C}$ for $4 \mathrm{~h}$ before conducting the experiment. About $2 \mathrm{~kg}$ of the growth substrate was added into compartments $\mathrm{A}$ and $\mathrm{C}$, and $1 \mathrm{~kg}$ of the growth substrate was added in compartment B.

\section{Design of the Competition Experiment}

A controlled growth chamber experiment was set up at the Langfang Experimental Station of CAAS. There were two competitive groups, namely F. bidentis-S. viridis and F. bidentisE. prostrata. Each group was exposed to three treatments (the monoculture of F. bidentis, the mixture of F. bidentis and the native plant, and the monoculture of the native plant). Two levels of AMF presence (AMF+) or absence (AMF-) were assigned to each treatment. Ten replicates per treatment were arranged (60 microcosms, in total, for each group). Before planting, a total of $40 \mathrm{~g}$ of the inoculum with about 2,400 spores mixed with $2 \mathrm{~kg}$ of the growth substrate was added in Compartments A and $\mathrm{C}\left(\mathrm{AMF}^{+}\right)$, respectively. The control treatment was inoculated with $40 \mathrm{~g}$ of the inoculum that was sterilized at $121^{\circ} \mathrm{C}$ for $30 \mathrm{~min}$ $\left(\mathrm{AMF}^{-}\right)$. After germination, additional plants were removed and only one seedling per compartment was kept. Rhizoboxes were kept in a growth chamber from July to September at $25^{\circ} \mathrm{C}$ under a $14 \mathrm{~h}$ light: $10 \mathrm{~h}$ dark photoperiod. Treatments were arranged in a completely randomized design. The water content of the soil in the rhizoboxes was kept at $25 \%$, and it was adjusted frequently by weight.

\section{${ }^{13} \mathrm{C}$ Labeling}

Plants were allowed to grow for 80 days prior to ${ }^{13} \mathrm{CO}_{2}$ application. For each treatment, half of the 10 replicates were used to assess the movement of $\mathrm{C}$ from the plants grown in Compartment A (donor) to the plants grown in Compartment $\mathrm{C}$ (receiver), and the rest of the five replicates were used to assess the inverse movement of $\mathrm{C}$ (i.e., from Compartment $\mathrm{C}$ to Compartment A). Before ${ }^{13} \mathrm{C}$ labeling, the surface of the soil was covered by a tinfoil but the aboveground plants were exposed to air. The donor plant was sealed in a transparent PVC container (red box) (Figure 1), ensuring enough penetration of light. To avoid air leakage out of the PVC container, the grooves in Compartments $\mathrm{A}$ and $\mathrm{C}$ were filled with water, and the PVC container was placed in a water-sealed tank. Meanwhile, three latex tubes (blue lines) were placed into the PVC container, and the gaps between the organic glass and latex tubes were sealed by glass cement. A ${ }^{13} \mathrm{C}$ pulse labeling was conducted according to the method of $\mathrm{Lu}$ et al. (2003). A tube that contained $5 \mathrm{~g}$ of $\mathrm{Na}_{2}^{13} \mathrm{CO}_{3}$ was placed into the PVC container. Before ${ }^{13} \mathrm{CO}_{2}$ application, the $\mathrm{CO}_{2}$ in the sealed container was completely absorbed by using $0.4 \mathrm{~mol}^{-1} \mathrm{NaOH}$ solution. Later, $0.36 \mathrm{~mol}$ $\mathrm{1}^{-1} \mathrm{H}_{2} \mathrm{SO}_{4}$ solution was slowly pumped into the tube by the latex tubing and it was allowed to react with $\mathrm{Na}_{2}^{13} \mathrm{CO}_{3}$. The reaction was controlled by a peristaltic pump and the ${ }^{13} \mathrm{CO}_{2}$ concentration was maintained at 400 ppm during the process, which was measured by a carbon dioxide concentration detector. An electric fan was placed in the donor compartment to make the ${ }^{13} \mathrm{CO}_{2}$ gas diffuse evenly in the PVC container. During this process, the released ${ }^{13} \mathrm{CO}_{2}$ was fixed with photosynthesis by 
synthesizing the carbohydrate inside the plants. Six hours later, the sealed container was removed after the remaining ${ }^{13} \mathrm{CO}_{2}$ was absorbed by $0.4 \mathrm{~mol} \mathrm{l}^{-1} \mathrm{NaOH}$. The control was labeled using $\mathrm{Na}_{2} \mathrm{CO}_{3}$. We labeled each plant three times, once in every 3 days (Liu et al., 2019).

\section{${ }^{15} \mathrm{~N}$ Labeling}

After ${ }^{13} \mathrm{C}$ labeling, plants were labeled with ${ }^{15} \mathrm{~N}$ according to the method of Cheng and Baumgartner (2004). For each plant, the leaves were inserted into three 2 -ml vials which were filled with $1.2 \mathrm{ml} 1 \%{ }^{15} \mathrm{~N}$ solution [99 atom $\%\left({ }^{15} \mathrm{NH}_{4}\right)_{2} \mathrm{SO}_{4}$ ] for $24 \mathrm{~h}$. The broad leaf of E. prostrata was curled tightly before it was inserted into the vials to avoid any damage. For each tested plant, three leaves were inserted into each vial. All the vials were covered with a tape to prevent the evaporation of $\left({ }^{15} \mathrm{NH}_{4}\right)_{2} \mathrm{SO}_{4}$.

\section{Measurements Colonization of AMF}

The percentage of mycorrhizal root colonization was estimated by a visual observation of fungal colonization after the roots were washed in $10 \% \mathrm{KOH}$ and stained with $0.05 \%$ Trypan blue in lactic acid (v/v) (Shi et al., 2006). The colonization of AMF on the roots of F. bidentis, S. viridis, and E. prostrata was determined by using the magnified intersection method of Mcgonigle et al. (1990). A total of 200 root segments were examined for each treatment. Ten replicates per treatment were used. The colonization of AMF in each treatment was calculated as follows:

Colonization $(\%)=\sum\left(0 \% \times \mathrm{N}_{0}+10 \% \times \mathrm{N}_{1}+20 \% \times \mathrm{N}_{2}\right.$ $\left.+\ldots .100 \% \times \mathrm{N}_{10}\right) / \mathrm{N}_{\text {Total }} \times 100 \%$,

where $\mathrm{N}_{\mathrm{i}}$ represents the numbers of root segments of the corresponding percentage colonization and $\mathrm{N}_{\text {Total }}$ represents the total numbers that were examined.

\section{Biomass and Corrected Index of Relative Competition Intensity}

Plant leaves (five leaves per plant) were collected 7 days after ${ }^{15} \mathrm{~N}$ labeling. The roots were washed to remove the soil particles. All shoots and roots of the exotic and the native plants were collected to measure their biomass.

The shoots and roots of F. bidentis, $S$. viridis, and E. prostrata were oven-dried at $80^{\circ} \mathrm{C}$ for $48 \mathrm{~h}$. The dry biomass of the roots and shoots of the three species were recorded to determine the ratio of roots to shoots and the relative biomass of roots and shoots. For each treatment, the data of the weight of the total dry plant were collected to determine the biomass. The corrected index of relative competition intensity (CRCI) was calculated following the method of Oksanen et al. (2006).

$$
\mathrm{CRCI}=\arcsin [(\mathrm{X}-\mathrm{Y}) / \max (\mathrm{X}, \mathrm{Y})]
$$

where $\mathrm{X}$ is the average biomass of an individual plant grown intraspecific and $\mathrm{Y}$ is the biomass of plants grown interspecific. The CRCI value $>0$ indicates that the competition has a negative effect, and the value $<0$ indicates that the competition has a positive effect on the target plant.

\section{Net Transfer of ${ }^{13} \mathrm{C}$ and ${ }^{15} \mathrm{~N}$}

Both the shoots and roots were ground with a Retsch Mixer Mill MM 200 (Verder Scientific Benelux NV, Aartselaar, Belgium). The concentration of $\mathrm{C}$ and $\mathrm{N}$ in the plants were measured with a CHN analyzer (LECO Corporation, St. Joseph, MI, USA). The concentrations of ${ }^{13} \mathrm{C}$ and ${ }^{15} \mathrm{~N}$ were measured with a mass spectrometer [Stable Isotope Facility, Institute of Applied Ecology (IAE), Chinese Academy of Science (CAS), China]. The net transfer of ${ }^{15} \mathrm{~N}$ and ${ }^{13} \mathrm{C}$ of $F$. bidentis was calculated based on the following formula:

$$
\text { Net transfer }(\%)=\left(\mathrm{T}_{1}-\mathrm{T}_{2}\right) \times 100 \text {, }
$$

where $\mathrm{T}_{1}$ is the percentage of ${ }^{15} \mathrm{~N}$ or ${ }^{13} \mathrm{C}$ transferred from $F$. bidentis to the native species, either to $S$. viridis or E. prostrata, and $\mathrm{T}_{2}$ is the percentage of ${ }^{15} \mathrm{~N}$ or ${ }^{13} \mathrm{C}$ transferred from the native species, either from $S$. viridis or E. prostrata, to F. bidentis.

The percent of ${ }^{15} \mathrm{~N}$ and ${ }^{13} \mathrm{C}$ transferred was calculated as follows (He et al., 2003; Zhang et al., 2015a):

$$
\begin{aligned}
& \mathrm{T}={ }^{15} \mathrm{~N}_{\text {receiver }} \times 100 /\left({ }^{15} \mathrm{~N}_{\text {receiver }}+{ }^{15} \mathrm{~N}_{\text {donor }}\right) \\
& \text { or } \\
& \mathrm{T}={ }^{13} \mathrm{C}_{\text {receiver }} \times 100 /\left({ }^{13} \mathrm{C}_{\text {receiver }}+{ }^{13} \mathrm{C}_{\text {donor }}\right) \\
& \text { where, }{ }^{15} \mathrm{~N}=\text { atom } \%{ }^{15} \mathrm{~N} \text { excess } \times \text { total } \mathrm{N} / \text { atom } \%{ }^{15} \mathrm{~N} \\
& \text { excess } \text { labeled } \mathrm{N} \\
& { }^{13} \mathrm{C}=\text { atom } \%{ }^{13} \mathrm{C} \text { excess } \times \text { total } \mathrm{C} / \text { atom } \%{ }^{13} \mathrm{C} \text { excess } \text { labeled }_{\text {la }} \\
& \mathrm{C} .
\end{aligned}
$$

\section{Statistical Analyses}

All statistical analyses were carried out using SPSS 19.0 (IBM, Armonk, New York). Before the analyses, all data were tested for normality by the Shapiro-Wilk test. All data met the normality distribution. The effects of AMF or the competition on plant growth indicators (i.e., biomass, root to shoot ratio, total $\mathrm{C}$ and $\mathrm{N}$ uptake plant ${ }^{-1}$, and $\mathrm{C} / \mathrm{N}$ ratio) of each plant species were tested by a one-way ANOVA. The interactive effects of the AMF and the competition of the mycorrhizal colonization on plant growth indicators of the plant species were tested by a two-way ANOVA. The analysis of Pearson's correlation coefficient of each plant species was used to determine the correlations of the rate of root colonization on plant growth indicators (i.e., biomass and the total content of $\mathrm{C}$ and $\mathrm{N}$ ).

\section{RESULTS}

\section{Colonization Rates}

In the $\mathrm{AMF}^{-}$treatment, no mycorrhizal colonization of $r$. intraradices was found in the roots of each of the three plant species. In the $\mathrm{AMF}^{+}$treatment, the mycorrhizal colonization of $R$. intraradices on $F$. bidentis was marginally higher in the mixture of $F$. bidentis and $S$. viridis than that in the monoculture of $F$. bidentis $\left[F_{(1,18)}=13.609, P=0.006\right]$ (Figure 2A). However, it was not significantly different in the mixture of $F$. bidentis and E. prostrata than that in the monoculture of $F$. bidentis $\left[F_{(1,18)}=\right.$ $0.031, P=0.866$ ] (Figure 2B). The mycorrhizal colonization of $R$. intraradices on $S$. viridis was significantly lower when it competed 

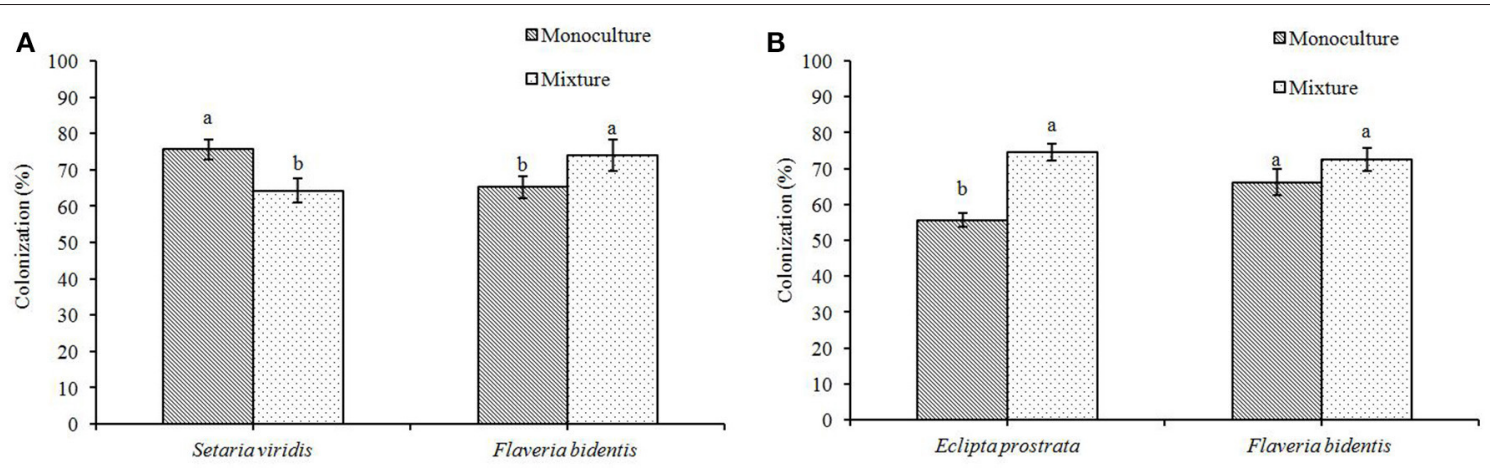

FIGURE 2 | The colonization rate of exotic plant $F$. bidentis and two native plants S. viridis (A) and E. prostate (B) when grown in monoculture or in mixture. Different lower case letters indicate significant difference between monoculture and mixture treatments at $P<0.05$. Error bar represent $\pm \mathrm{SE}$ of mean $(n=10)$.

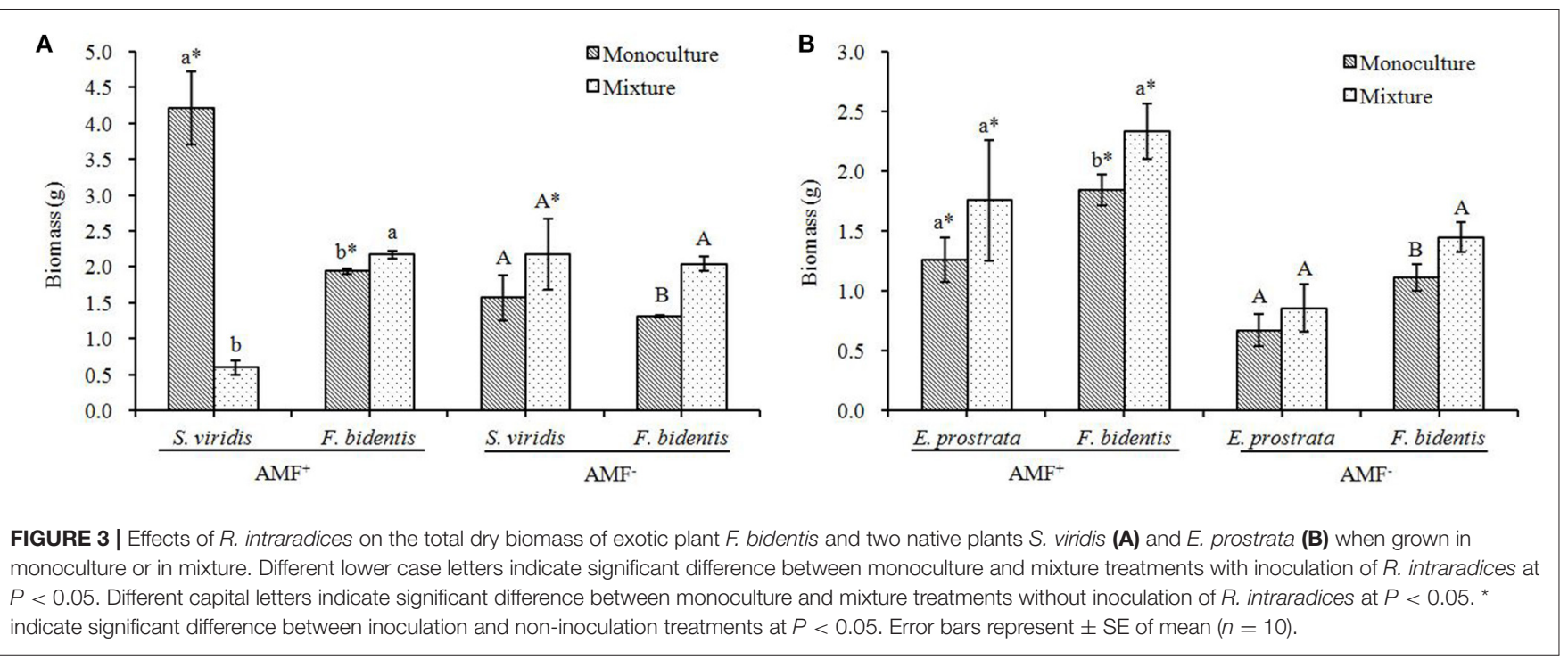

with $F$. bidentis than that when it was grown in the monoculture treatment $\left[F_{(1,18)}=36.470, P<0.001\right]$ (Figure 2A). However, the mycorrhizal colonization of $R$. intraradices on $E$. prostrata was significantly higher when it competed with $F$. bidentis than that when it was grown in the monoculture treatment $\left[F_{(1,18)}=\right.$ 204.833, $P<0.001$ ] (Figure 2B).

\section{The Effect of $\boldsymbol{R}$. intraradices on the Growth of Plant \\ Biomass}

In the $\mathrm{AMF}^{+}$treatment, compared to the monoculture, the biomass of $F$. bidentis increased when it grew with $S$. viridis (Figure 3A) or E. prostrate (Figure 3B) [S. viridis: $F_{(1,18)}=$ 33.547, $P=0.004$; E. prostrate: $\left.F_{(1,18)}=10.034, P=0.034\right]$ while it showed different impacts on the two native species: it decreased the biomass of $S$. viridis $\left[F_{(1,18)}=144.743, P<0.001\right]$ but showed no effect on that of E. prostrate $\left[F_{(1,18)}=2.552, P\right.$ $=0.185]$.

In the $\mathrm{AMF}^{-}$treatment, compared to the monoculture, the biomass of $F$. bidentis increased when it grew with $S$. viridis or E. prostrate $\left[S\right.$. viridis: $F_{(1,18)}=154.331, P<0.001 ;$ E. prostrate:
$\left.F_{(1,18)}=154.331, P<0.001\right]$, but showed no effect on that of the native species $\left[S\right.$. viridis: $F_{(1,18)}=3.271, P=0.145$; . prostrate: $\left.F_{(1,18)}=1.804, P=0.250\right]$ (Figure 3).

\section{Corrected Index of Relative Competition Intensity}

In the $\mathrm{AMF}^{+}$treatment, the CRCI of both F. bidentis and $E$. prostrate is $<0$, while that of $S$. viridis is $>0$, indicating that the competition had a positive effect on the growth of both F. bidentis and $E$. prostrate, while it showed a negative effect on the growth of $S$. viridis (Figure 4). In the $\mathrm{AMF}^{-}$treatment, the CRCI of both $F$. bidentis and the two native species is $<0$, suggesting that the competition had a positive effect on their growth.

Compared to $\mathrm{AMF}^{-}$treatment, the $\mathrm{AMF}^{+}$treatment enhanced the positive effect of competition on $F$. bidentis when F. bidentis competed with $S$. viridis $\left[F_{(1,18)}=205.121, P<0.001\right]$ (Figure 4A), while it showed no effect on $F$. bidentis when $F$. bidentis competed with $E$. prostrate $\left[F_{(1,18)}=0.008, P=0.932\right]$ (Figure 4B). Meanwhile, the effect of competition on the growth of $S$. viridis shifted from positive in the $\mathrm{AMF}^{-}$treatment to negative in the $\mathrm{AMF}^{+}$treatment. 

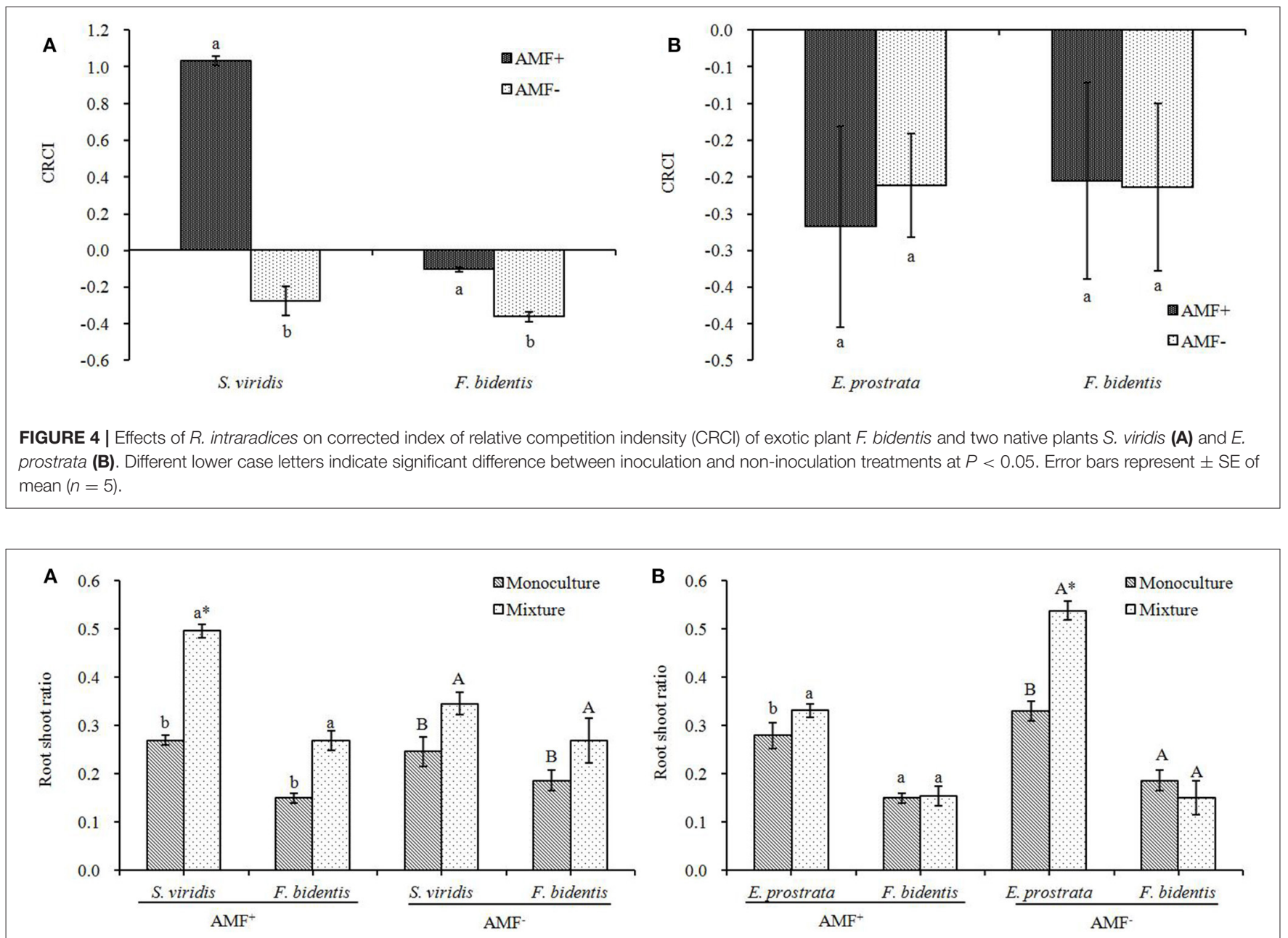

FIGURE 5 | Effects of $R$. intraradices on the root to shoot ratio of exotic plant $F$. bidentis and two native plants $S$. viridis (A) and E. prostrata (B) when grown in monoculture or in mixture. Different lower case letters indicate significant difference between monoculture and mixture treatments with inoculation of $R$. intraradices at $P<0.05$. Different capital letters indicate significant difference between monoculture and mixture treatments without inoculation of $R$. intraradices at $P<0.05$. *indicate significant difference between inoculation and non-inoculation treatments at $P<0.05$. Error bars represent \pm SE of mean $(n=10)$.

\section{Ratio of Root to Shoot}

The competition increased the ratio of roots to shoots in $F$. bidentis and in $S$. viridis both in the presence and absence of AMF ( $F=39.130$ or $22.704, P<0.001)$. Compared to the monoculture, the ratio of roots to shoots in $F$. bidentis significantly increased when $F$. bidentis grew with $S$. viridis, (Figure 5A) $\left[\mathrm{AMF}^{-}: F_{(1,18)}\right.$ $\left.=8.224, P=0.046 ; \mathrm{AMF}^{+}: F_{(1,18)}=76.563, P=0.001\right]$, while there was no change when $F$. bidentis grew with $E$. prostrata (Figure 5B) $\left[\mathrm{AMF}^{-}: F_{(1,18)}=2.327, P=0.202 ; \mathrm{AMF}^{+}: F_{(1,18)}\right.$ $=0.062, P=0.815]$. Furthermore, the ratio of roots to shoots in E. prostrata $\left[\mathrm{AMF}^{-}: F_{(1,18)}=165.375, P<0.001 ; \mathrm{AMF}^{+}: F_{(1,18)}\right.$ $=9.143, P=0.039]$ and $S$. viridis $\left[\mathrm{AMF}^{-}: F_{(1,18)}=19.149, P\right.$ $\left.=0.012 ; \mathrm{AMF}^{+}: F_{(1,18)}=462.400, P<0.001\right]$ in the mixture treatment was significantly higher than that in the monoculture when they grew with F. bidentis (Figure 5).

Compared to the $\mathrm{AMF}^{-}$treatment, the ratio of roots to shoots of $S$. viridis in the mixture of the $\mathrm{AMF}^{+}$ treatment increased (Figure 5A) $\left[F_{(1,18)}=77.885, \quad P=\right.$
0.001] while that of $E$. prostrata decreased $\left[F_{(1,18)}=\right.$ 202.316, $P<0.001]$ in the mixture of the $\mathrm{AMF}^{+}$treatment (Figure 5B).

\section{Carbon Content in Plant Tissue}

In the $\mathrm{AMF}^{+}$treatment, the content of $\mathrm{C}$ in $S$. viridis in the mixture was lower than that in the monoculture $\left[F_{(1,18)}=\right.$ 255.297, $P<0$ 0001] (Figure 6A) while that of E. prostrata in the mixture was higher than that in the monoculture $\left[F_{(1,18)}=\right.$ 53.993, $P=0.002$ ] (Figure 6B). In F. bidentis, compared to the monoculture treatment, the content of $\mathrm{C}$ increased when it was grown with $E$. prostrata $\left[F_{(1,18)}=9.803, P=0.035\right]$ but decreased when it was grown with $S$. viridis $\left[F_{(1,18)}=11.616, P=0.027\right]$ (Figures 6A,B).

In the $\mathrm{AMF}^{-}$treatment, no significant difference in the content of $\mathrm{C}$ of the two native species was found between the monoculture treatment and the mixture treatment (Figures 6A,B) [S. viridis: $F_{(1,18)}=1.944, P=0.236$; E. prostrata: 


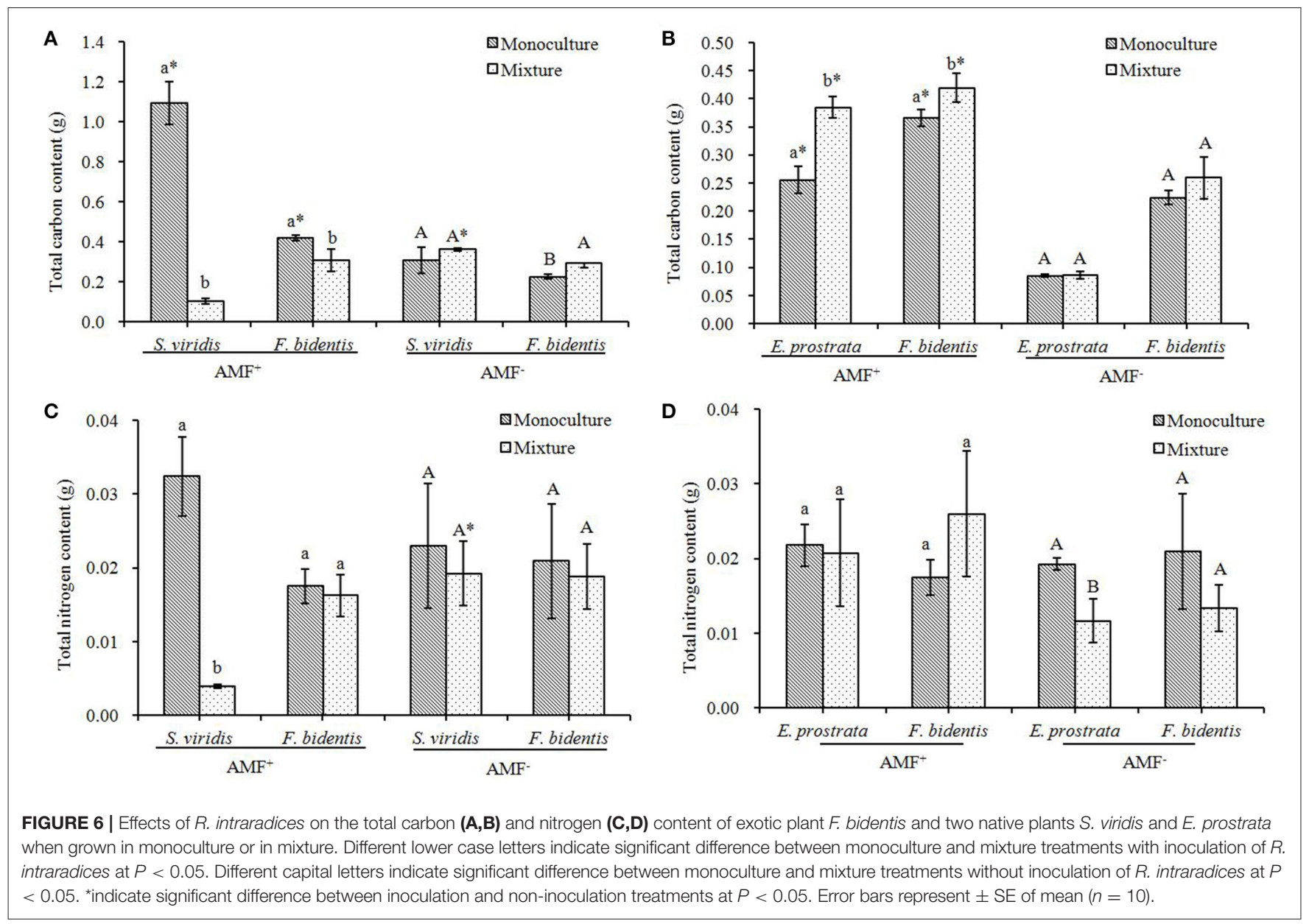

$\left.F_{(1,18)}=0.066, P=0.810\right]$. The content of $\mathrm{C}$ in F. bidentis increased when it was grown with $S$. viridis compared to when it was grown in the monoculture $\left[F_{(1,18)}=20.910, P=0.010\right]$ (Figure 6A), while no significant difference was found between the monoculture and the mixture with E. prostrata $\left[F_{(1,18)}=\right.$ 2.399, $P=0.196$ ] (Figures 6A,B).

The inoculation of $R$. intraradices showed different effects on the content of $\mathrm{C}$ in $\mathrm{F}$. bidentis when it was grown in the mixture treatment with the two different native species: the content of $\mathrm{C}$ in $F$. bidentis increased when it was grown with $E$. prostrata $\left[F_{(1,18)}=488.169, P<0.001\right]$, but no change was found when it was grown with $S$. viridis $\left[F_{(1,18)}=0.436, P=0.437\right]$ (Figures 6A,B).

\section{Nitrogen Content in the Plant Tissue}

In the $\mathrm{AMF}^{+}$treatment, no significant difference was found in the content of $\mathrm{N}$ in $F$. bidentis [in the mixture treatment with $S$. viridis: $F_{(1,18)}=0.355, P=0.583$; in the mixture treatment with $E$. prostrata: $\left.F_{(1,18)}=2.792, P=0.170\right]$ and in $E$. prostrata $\left[F_{(1,18)}=0.065, P_{N}=0.811\right]$ between the monoculture treatment and the mixture treatment, while the content of $\mathrm{N}$ in $S$. viridis significantly decreased in the mixture treatment $\left[F_{(1,18)}=\right.$ 84.754, $P_{N}=0.001$ ] (Figures 6C,D).
In the $\mathrm{AMF}^{-}$treatment, no significant difference was found in the content of $\mathrm{N}$ in $F$. bidentis [in the mixture treatment with S. viridis: $F_{(1,18)}=0.163, P=0.707$; in the mixture treatment with $E$. prostrata: $\left.F_{(1,18)}=2.474, P=0.191\right]$ and in S. viridis $\left[F_{(1,18)}=0.456, P=0.537\right]$ between the monoculture treatment and the mixture treatment, while the content of $\mathrm{N}$ in $E$. prostrata significantly decreased in the mixture treatment $\left[F_{(1,18)}\right.$ $=19.099, P=0.012$ ] (Figures 6C,D).

The inoculation of $R$. intraradices showed no significant different effects on the content of $\mathrm{N}$ in F. bidentis and E. prostrata, regardless of the fact that they were grown in the monoculture $\left[F_{(1,18)}=0.533\right.$ or $2.455, P=0.506$ or 0.192$]$ or in the mixture $\left[F_{(1,18)}=5.907\right.$ or $4.117, P=0.072$ or 0.112$]$ treatments, but the content of $\mathrm{N}$ in $S$. viridis decreased in the inoculation treatment of $R$. intraradices when it was grown in the mixture with $F$. bidentis $\left[F_{(1,18)}=37.146, P=0.004\right]$ (Figures 6C,D).

\section{Carbon and N Transfer Between F. bidentis and Native Plant Species}

In the $\mathrm{AMF}^{+}$treatment, the ${ }^{13} \mathrm{C}$ and ${ }^{15} \mathrm{~N}$ transfer rates from $F$. bidentis to $S$. viridis were 2.67 and $2.14 \%$, respectively, while they were 2.54 and $0.98 \%$ from $S$. viridis to F. bidentis, respectively 
TABLE 1 | Carbon and nitrogen transfer between F. bidentis and two native plants (S. viridis and E. prostrata) mediated by R. intraradices.

\begin{tabular}{|c|c|c|c|c|c|c|c|}
\hline \multirow[t]{2}{*}{ Groups } & \multirow[t]{2}{*}{$\begin{array}{l}\text { With }(+) / \text { without } \\
(-) R \text {. intraradices }\end{array}$} & \multirow[t]{2}{*}{ Donor } & \multirow[t]{2}{*}{ Receivers } & \multicolumn{2}{|c|}{ Transfer rate (\%) } & \multicolumn{2}{|c|}{$\begin{array}{l}\text { Net transfer rate (\%) from } F \text {. } \\
\text { bidentis to native plant }\end{array}$} \\
\hline & & & & ${ }^{13} \mathrm{C}$ & ${ }^{15} \mathrm{~N}$ & ${ }^{13} \mathrm{C}$ & ${ }^{15} \mathrm{~N}$ \\
\hline \multirow[t]{4}{*}{ Group 1} & $\mathrm{AMF}^{+}$ & F. bidentis & S. viridis & $2.67 \pm 0.11$ & $2.14 \pm 0.04$ & $0.12 \pm 0.01$ & $1.05 \pm 0.02$ \\
\hline & $\mathrm{AMF}^{+}$ & S. viridis & F. bidentis & $2.54 \pm 0.06$ & $0.98 \pm 0.02$ & & \\
\hline & $\mathrm{AMF}^{-}$ & F. bidentis & S. viridis & $0.02 \pm 0.01$ & $0.01 \pm 0.002$ & $0.01 \pm 0.003$ & $0.001 \pm 0.001$ \\
\hline & $\mathrm{AMF}^{-}$ & S. viridis & F. bidentis & $0.01 \pm 0.002$ & $0.009 \pm 0.001$ & & \\
\hline \multirow[t]{4}{*}{ Group 2} & $\mathrm{AMF}^{+}$ & F. bidentis & E. prostrata & $3.26 \pm 0.12$ & $2.99 \pm 0.21$ & $-0.11 \pm 0.01$ & $-0.48 \pm 0.02$ \\
\hline & $\mathrm{AMF}^{+}$ & E. prostrata & F. bidentis & $3.37 \pm 0.20$ & $4.29 \pm 0.56$ & & \\
\hline & $\mathrm{AMF}^{-}$ & F. bidentis & E. prostrata & $0.015 \pm 0.001$ & $0.013 \pm 0.002$ & $0.005 \pm 0.001$ & $-0.001 \pm 0.001$ \\
\hline & $\mathrm{AMF}^{-}$ & E. prostrata & F. bidentis & $0.010 \pm 0.001$ & $0.014 \pm 0.002$ & & \\
\hline
\end{tabular}

TABLE 2 | The correlation of colonization rate with biomass and $\mathrm{C}$ and $\mathrm{N}$ content.

\begin{tabular}{|c|c|c|c|c|}
\hline Groups & Plant species & Biomass & Total carbon content & Total nitrogen content \\
\hline \multirow[t]{2}{*}{ Group 1} & F. bidentis & 0.78 & -0.74 & 0.77 \\
\hline & S. viridis & $0.92^{\star}$ & $0.96^{\star}$ & $0.90^{*}$ \\
\hline \multirow[t]{2}{*}{ Group 2} & F. bidentis & -0.29 & 0.08 & -0.50 \\
\hline & E. prostrata & 0.65 & $-0.924^{\star}$ & 0.31 \\
\hline
\end{tabular}

*indicate the significantly correlated of colonization rate with biomass and $C$ and $N$ content at $P<0.05$.

(Table 1). The net transfer rates of ${ }^{13} \mathrm{C}$ and ${ }^{15} \mathrm{~N}$ from $F$. bidentis to $S$. viridis were 0.12 and $1.05 \%$, respectively.

The transfer of ${ }^{13} \mathrm{C}$ and ${ }^{15} \mathrm{~N}$ was bidirectional between $F$. bidentis and E. prostrata. In the $\mathrm{AMF}^{+}$treatment, the transfer rates of ${ }^{13} \mathrm{C}$ and ${ }^{15} \mathrm{~N}$ from $F$. bidentis to E. prostrata were 3.26 and $2.99 \%$, respectively, while they were 3.37 and $4.29 \%$ from $E$. prostrata to $F$. bidentis, respectively (Table 1 ). The net transfer rates of ${ }^{13} \mathrm{C}$ and ${ }^{15} \mathrm{~N}$ from $F$. bidentis to E. prostrata were -0.11 and $-0.48 \%$, respectively.

\section{The Correlation of Colonization Rate With Biomass and the Contents of $\mathbf{C}$ and $\mathbf{N}$}

When F. bidentis competed with $S$. viridis, the colonization rate of $R$. intraradices on $S$. viridis was positively correlated with its biomass $(r=0.92, P=0.010)$, C content $(r=0.96, P=$ $0.003)$, and $\mathrm{N}$ content $(r=0.90, P=0.014)$ (Table 2). When $F$. bidentis competed with E. prostrata, the colonization rate of $R$. intraradices on $E$. prostrata was negatively correlated with its $\mathrm{C}$ content $(r=-0.92, P=0.008)$.

\section{DISCUSSION}

Arbuscular mycorrhizal fungi played a critical role in the successful invasion of certain exotic species (Klironomos, 2002). AMF could be conducive to invasiveness if exotic plants benefited more from these services than the native plants, or if the exotic plants could disrupt the mutualism between the AMF and the native plants (Reinhart et al., 2017). Our study showed that $R$. intraradices could colonize on both the exotic and the native plant species. The effects of $R$. intraradices on the competitiveness of $F$. bidentis depend on the type of native species present in the habitat. To be specific, the CRCI of both F. bidentis and E. prostrata did not change when they were grown in the inoculated mixture with $R$. intraradices. However, when $F$. bidentis and $S$. viridis were grown in a mixture, the inoculation of $R$. intraradices amplified the positive effect on $F$. bidentis but showed a negative effect on $S$. viridis. These divergent responses caused differences in the nutrient uptake and nutrient transfer between the invasive and the native species (Reinhart and Anacker, 2014; Veresoglou and Rillig, 2014).

Resource sharing in plant communities does occur through CMNs formed by the AMF (Carey and Callaway, 2004; HøghJensen et al., 2005) so that CMNs can mediate interactions among the connected plants (Chiariello et al., 1982; Wilson et al., 2006; Janos, 2007). Recently, more and more studies focus on finding whether CMNs transfer nutrients among all the interconnected plants or enhance the competition among them (Weremijewicz and Janos, 2013). Weremijewicz et al. (2018) pointed out that intact CMNs could amplify the intraspecific competition within Andropogongerardii population in consequence of improved mineral nutrition. Simard et al. (1997) suggested that the net transfer of $\mathrm{C}$ could affect the performance of plants and the magnitude of the net transfer of nutrients could regulate through the source-sink relationship. Carey and Callaway (2004) suggested that, when exotic Centaurea maculosa grew with their native neighbors, $\mathrm{C}$ was transferred from the native species to the exotic species, which may be the important mechanism through which the invasive plants outcompete their neighbors. In this study, we found that the transfer of $\mathrm{C}$ and $\mathrm{N}$ via AM hyphal links did occur between the exotic and native plants. However, the net transfer of $\mathrm{C}$ and $\mathrm{N}$ was not always from the native species to the invasive species. To be specific, ${ }^{13} \mathrm{C}$ and ${ }^{15} \mathrm{~N}$ were transferred from $F$. bidentis to $S$. viridis when $F$. bidentis was grown with S. viridis, while ${ }^{13} \mathrm{C}$ and ${ }^{15} \mathrm{~N}$ were transferred from E. prostrata 
to $F$. bidentis when $F$. bidentis was grown with E. prostrata. This divergence suggested that the effects of CMN on plant interactions depend on the type of plant species involved and the interaction with $F$. bidentis, when the native species is highly species-specific. Some researchers documented that plant traits, such as photosynthetic pathways, growth forms, and competitor strategies, were associated with the community and function of AMF (Meisner et al., 2014; Davison et al., 2020). In this study, the two native plant species, $S$. viridis and E. prostrata, have different photosynthetic pathways and root systems; $S$. viridis is a $\mathrm{C}_{4}$ plant and its root system is a fibrous root system, while E. prostrata is a $\mathrm{C}_{3}$ plant and its root system is a tap root system. These differences between $S$. viridis and E. prostrata may account for the transfer rate of $\mathrm{C}$ and $\mathrm{N}$ transferred by CMNs. Importantly, compared to the $\mathrm{AMF}^{-}$treatment, when F. bidentis and $S$. viridis were grown in an inoculated mixture of $R$. intraradices, they amplified the positive effect on $F$. bidentis, while ${ }^{13} \mathrm{C}$ and ${ }^{15} \mathrm{~N}$ were transferred from $F$. bidentis to $S$. viridis. When $F$. bidentis was grown with $E$. prostrata, the inoculation of $R$. intraradices had no effect on $F$. bidentis though ${ }^{13} \mathrm{C}$ and ${ }^{15} \mathrm{~N}$ were transferred from $E$. prostrata to F. bidentis. Our findings indicated that the $\mathrm{C}$ or $\mathrm{N}$ transferred by CMNs is not related to the competitive growth of F. bidentis. Our result is consistent with some previous results which stated that the $\mathrm{C}$ or $\mathrm{N}$ transferred by CMNs was not the key factors that influence the plant competition (Zabinski et al., 2002; Milkereit et al., 2018).

Increasing evidence suggested that the colonization of AMF on the roots might be a good predictor of plant growth and nutrient acquisition (Bunn et al., 2015; Zhang et al., 2017). In our study, different changes were found in the colonization rate of $R$. intraradices on the two native species in response to the competition with F. bidentis. Specifically, the colonization rate of $R$. intraradices on $S$. viridis was lower in the mixture treatment than in the monoculture treatment, while it was inverse in $E$. prostrata. Moreover, this difference in the colonization rate in response to the inoculation of $R$. intraradices was correlated with the differences in the nutrient uptake and growth strategies. In $S$. viridis, compared to the monoculture, the competition with $F$. bidentis decreased its $\mathrm{C}$ and $\mathrm{N}$ content in the $\mathrm{AMF}^{+}$treatment. Correlation analysis showed that the colonization rate of $R$. intraradices on $S$. viridis was positively correlated with its total $\mathrm{C}$ content and $\mathrm{N}$ content. Such a decrease in the content of $\mathrm{C}$ in $S$. viridis may inhibit the growth of hyphae, which colonized the roots of $S$. viridis and then reduced the plant nutrient uptake (Cloos et al., 2014). In E. prostrate, the colonization rate of $R$. intraradices was negatively correlated with the total $C$ content. The increase in the colonization rate of $R$. intraradices on $E$. prostrate in the mixture treatment may increase the $C$ transfer rate from plants to the AMF, which may benefit the growth of hyphae that colonized on the roots of E. prostrate and then

\section{REFERENCES}

Babikova, Z., Gilbert, L., Bruce, T. J. A., Birkett, M., Caulfield, J. C., Woodcock, C., et al. (2013). Underground signals carried through common mycelial enhance the plant nutrient uptake. Interestingly, the changed trends of $\mathrm{N}$ content, both in S. viridis and in E. prostrata, were consistent with the trends of their biomass in mixture treatment, respectively, in the presence of AMF. The results suggested that AMF compete with plants for $\mathrm{N}$, as has been shown in the previous studies (Brooks, 2003; Janos, 2007; Smith et al., 2009; Johnson et al., 2015). Therefore, the invasion of F. bidentis affected the growth of the native plants by shifting its $\mathrm{N}$ uptake in the presence of AMF.

\section{CONCLUSION}

Carbon and $\mathrm{N}$ transfer via AM hyphal links did occur between the exotic and native plants. However, the net transfer of $\mathrm{C}$ and $\mathrm{N}$ was not always from native species to invasive species, suggesting that the $\mathrm{C}$ or $\mathrm{N}$ transferred by CMNs was not the key factor that influences the competition between the exotic F. bidentis and the native species. Indeed, when $F$. bidentis competed with $S$. viridis or E. prostrata, the F. bidentis affected the growth of the native plant by shifting its $\mathrm{N}$ uptake in the presence of $R$. intraradices.

\section{DATA AVAILABILITY STATEMENT}

The original contributions presented in the study are included in the article/Supplementary Material, further inquiries can be directed to the corresponding author/s.

\section{AUTHOR CONTRIBUTIONS}

All authors contributed to the formulation, writing, and revision of this manuscript and made direct intellectual contributions. They all approve of its publication.

\section{FUNDING}

This research was funded by the National Natural Science Foundation of China, Grant No. 31972343; Hebei National Natural Science Foundation, Grant No. C2019201059.

\section{ACKNOWLEDGMENTS}

We thank Prof. Runjin Liu, Qingdao Agricultural University, for providing the inoculum of Rhizophagus intraradices.

\section{SUPPLEMENTARY MATERIAL}

The Supplementary Material for this article can be found online at: https://www.frontiersin.org/articles/10.3389/fevo. 2021.625519/full\#supplementary-material 
extend bioactive zones of allelochemicals in soils. PLoS ONE. 6:e27195. doi: 10.1371/journal.pone.0027195

Bennett, J. A., Maherali, H., Reinhart, K. O., Lekberg, Y., Hart, M. M., and Klironomos, J. (2017). Plant-soil feedbacks and mycorrhizal type influence temperate forest population dynamics. Science 355, 181-184. doi: 10.1126/science.aai8212

Bever, J. D. (2002). Host-specificity of AM fungal population growth rates can generate feedback on plant growth. Plant Soil. 244, 281-290. doi: $10.1023 / \mathrm{A}: 1020221609080$

Brooks, M. L. (2003). Effects of increased soil nitrogen on the dominance of alien annual plants in the mojave desert. J. Appl. Ecol. 40, 344-353. doi: $10.1046 / j .1365-2664.2003 .00789 . x$

Bücking, H., Hans, R., and Heyser, W. (2007). "The apoplast of ectomycorrhizal roots-site of nutrient uptake and nutrient exchange between the symbiotic partners," in The Apoplast of Higher Plants: Compartment of Storage, Transport and Reactions. eds B. Sattelmacher and W. J. Horst (Dordrecht: Springer). doi: 10.1007/978-1-4020-5843-1_7

Bücking, H., Mensah, J. A., and Fellbaum, C. R. (2016). Common mycorrhizal networks and their effect on the bargaining power of the fungal partner in the arbuscular mycorrhizal symbiosis. Commun. Integr. Biol. 9:e1107684. doi: $10.1080 / 19420889.2015 .1107684$

Bunn, R. A., Ramsey, P. W., and Lekberg, Y. (2015). Do native and invasive plants differ in their interactions with arbuscular mycorrhizal fungi? A meta-analysis. J. Ecol. 103, 1547-1556. doi: 10.1111/1365-2745.12456

Callaway, R. M., Cipollini, D., Barto, K., Thelen, G. C., Hallett, S. G., Prati, D., et al. (2008). Novel weapons: invasive plant suppresses fungal mutualists in America but not in its native Europe. Ecology 89, 1043-1055. doi: 10.1890/07-0370.1

Carey, E. V., and Callaway, M. R. M. (2004). Mycorrhizae transfer carbon from a native grass to an invasive weed: evidence from stable isotopes and physiology. Plant Ecol. 172, 133-141. doi: 10.1023/B:VEGE.0000026031.14086.f1

Chen, Y. L., Gao, X. M., Liang, Y., Zheng, T. X., San, W. G., and Tang, T. G. (2004). An alert regarding biological invasion by a new exotic plant, Flaveria bidentis, and strategies for its control. Chin. Biodivers. 12, 274-279. doi: 10.17520/biods.2004033

Cheng, X., and Baumgartner, K. (2004). Survey of arbuscular mycorrhizal fungal communities in northern california vineyards and mycorrhizal colonization potential of grapevine nursery stock. Am. Soc. Hortic. Sci. 39, 1702-1706. doi: 10.21273/HORTSCI.39.7.1702

Chiariello, N. R., Hickman, J. C., and Mooney, H. A. (1982). Endomycorrhizal role for interspecific transfer of phosphorus in a community of annual plants. Science 217, 941-943. doi: 10.1126/science.217.4563.941

Cloos, A. J., Pfeffer, P. E., Fellbaum, C. R., Mensah, J. A., Bücking, H., Kiers, E. T., et al. (2014). Fungal nutrient allocation in common mycorrhizal networks is regulated by the carbon source strength of individual host plants. New Phytol. 203, 646-656. doi: 10.1111/nph.12827

Davison, J., García de León, D., Zobel, M., Moora, M., Bueno, C. G., Barceló, M., et al. (2020). Plant functional groups associate with distinct arbuscular mycorrhizal fungal communities. New Phytol. 226, 1117-1128. doi: $10.1111 /$ nph. 16423

Fitter, A. H., Hodge, A., Daniell, T. J., and Robinson, D. (1999). Resource sharing in plant-fungus communities: did the carbon move for you? Trends Ecol. Evol. 14:70. doi: 10.1016/S0169-5347(98)01540-7

Gerz, M., Bueno, C. G., Ozinga, W. A., Zobel, M., and Moora, M. (2018). Niche differentiation and expansion of plant species are associated with mycorrhizal symbiosis. J. Ecol. 106, 254-264. doi: 10.1111/1365-2745.12873

He, X. H., Critchley, C., and Bledsoe, C. (2003). Nitrogen transfer within and between plants through common mycorrhizal networks (CMNs). Crit. Rev. Plant 22, 531-567. doi: 10.1080/713608315

Høgh-Jensen, H., Nielsen, B., and Thamsborg, S. M. (2005). Productivity and quality, competition and facilitation of chicory in ryegrass/legume-based pastures under various nitrogen supply levels. Eur. J. Agron. 24, 247-256. doi: 10.1016/j.eja.2005.10.007

Janos, D. P. (2007). Plant responsiveness to mycorrhizas differs from dependence upon mycorrhizas. Mycorrhiza 17, 75-91. doi: 10.1007/s00572-0060094-1

Ji, Y. H., Liu, R. J., and Li, M. (2015). Arbuscular mycorrhizal colonization and development of Flaveria bidentis under natural invasive conditions. Mycosystema 34, 82-90. doi: 10.13346/j.mycosystema.130208
Johnson, N. C., Wilson, G. W. T., Wilson, J. A., Miller, R. M., and Bowker, M. A. (2015). Mycorrhizal phenotypes and the law of the minimum. New Phytol. 205, 1473-1484. doi: 10.1111/nph.13172

Kiers, E. T., Duhamel, M., Beesetty, Y., Mensah, J. A., Franken, O., Verbruggen, E., et al. (2011). Reciprocal rewards stabilize cooperation in the mycorrhizal symbiosis. Science 333, 880-882. doi: 10.1126/science.1208473

Klironomos, and John, N. (2002). Feedback with soil biota contributes to plant rarity and invasiveness in communities. Nature 417, 67-70. doi: $10.1038 / 417067$ a

Lekberg, Y., Gibbons, S. M., Rosendahl, S. R., and Ramsey, P. W. (2013). Severe plant invasions can increase mycorrhizal fungal abundance and diversity. ISME J. 7, 1424-1433. doi: 10.1038/ismej.2013.41

Lekberg, Y., Hammer, C. E., and Olsson, P. A. (2010). Plants as resource islands and storage units - adopting the mycocentric view of arbuscular mycorrhizal networks. FEMS Microbiol. Ecol. 74, 336-345. doi: 10.1111/j.1574-6941.2010.00956.x

Lin, G. G., McCormack, M. L., and Guo, D. L. (2015). Arbuscular mycorrhizal fungal effects on plant competition and community structure. J. Ecol. 103, 1224-1232. doi: 10.1111/1365-2745.12429

Liu, D., Ruan, G. W., Shi, Q. Y., and Feng, J. L. (2019). Determination of halogen in zinc oxide concentrate products by burner-ion chromatography. Guangdong Chem. Ind. 46, 170-172.

Lu, Y., Watanabe, A., and Kimura, M. (2003). Carbon dynamics of rhizodeposits, root-and shoot-residues in a rice soil. Soil Biol. Biochem. 35, 1223-1230. doi: 10.1016/S0038-0717(03)00184-6

Mcgonigle, T. P., Miller, M. H., Evans, D. G., and Swan, G. L. F. A. (1990). A new method which gives an objective measure of colonization of roots by vesicular-arbuscular mycorrhizal fungi. New Phytol. 115, 495-501. doi: 10.1111/j.1469-8137.1990.tb00476.x

Meisner, A., Gera Hol, W. H., De Boer, W., Krumins, J. A., Wardle, D. A., and andVan der Putten, W. H. (2014). Plant-soil feedbacks of exotic plant species across life forms: a meta-analysis. Biol. Invasions. 16, 2551-2561. doi: 10.1007/s10530-014-0685-2

Milkereit, J., Frossard, E., Stoll, P., Wagg, C., and Niklaus, P. A. (2018). Experimental disconnection from common mycorrhizal networks has little effect on competitive interactions among common temperate grassland species. J. Ecol. 106, 2332-2343. doi: 10.1111/1365-2745.12984

Oksanen, L., Sammul, M., and Magi, M. (2006). On the indices of plant-plant competition and their pitfalls. Oikos 112, 149-155. doi: 10.1111/j.0030-1299.2006.13379.x

Olsen, G. E. (1954). Fresh vs. pre-processed vegetables: comparative cost and availability. J. Am. Dent. Assoc. 30:762.

Pringle, A., Adams, R. I., Cross, H. B., and Bruns, T. D. (2009). The ectomycorrhizal fungus Amanita phalloides was introduced and is expanding its range on the west coast of North America. Mol. Ecol. 18, 817-833. doi: 10.1111/j.1365-294X.2008.04030.x

Reinhart, K. O., and Anacker, B. L. (2014). More closely related plants have more distinct mycorrhizal communities. Aob Plants. 6:plu051. doi: 10.1093/aobpla/plu051

Reinhart, K. O., Lekberg, Y., Klironomos, J., and Maherali, H. (2017). Does responsiveness to arbuscular mycorrhizal fungi depend on plant invasive status? Ecol. Evol. 7, 6482-6492. doi: 10.1002/ece3.3226

Ren, Y. P., Jiang, S., Gu, S., Wang, Y. Z., and Zheng, S. X. (2008). Advances in Flaveria bidentis (L.) Kuntze, a new exotic plant. J. Trop. Subtrop. Bot. $16,390-396$.

Selosse, M., Richard, F., He, X., and Simard, S. W. (2006). Mycorrhizal networks: desliaisons dangereuses? Trends Ecol. Evol. 21, 621-628. doi: $10.1016 /$ j.tree.2006.07.003

Selosse, M. A., Bocayuva, M. F., Kasuya, M. C. M., and Courty, P. E. (2016). "Mixotrophy in mycorrhizal plants: extracting carbon from mycorrhizal networks," in Molecular Mycorrhizal Symbiosis. ed F. Martin (Hoboken, NJ: John Wiley), 451-471.

Shi, Z. Y., Chen, Y. L., Feng, G., Liu, R. J., Christie,P., and Li, X.L. (2006). Arbuscular mycorrhizal fungi associated with the Meliaceae on Hainan island, China Mycorrhiza. 16, 81-87. doi: 10.1007/s00572-005-0017-6

Simard, S. W., Perry, D. A., Jones, M. D., Myrold, D. D., Durall, D. M., and Molina, R. (1997). Net transfer of carbon between ectomycorrhizal tree species in the field. Nature 388, 579-582. doi: 10.1038/41557 
Smith, F. A., Grace, E. J., and Smith, S. E. (2009). More than a carbon economy: nutrient trade and ecological sustainability in facultative arbuscular mycorrhizal symbioses. New Phytol. 182, 347-358. doi: 10.1111/j.1469-8137.2008.02753.x

Song, Y. Y., Zeng, R. S., Xu, J. F., Li, J., Shen, X., and Yihdego, W. G. (2010). Interplant communication of tomato plants through underground common mycorrhizal networks. PLoS ONE 5:e13324. doi: 10.1371/journal.pone. 0013324

Stinson, K. A., Campbell, S. A., Powell, J. R., Wolfe, B. E., Callaway, R. M., Thelen, G. C., et al. (2006). Invasive plant suppresses the growth of native tree seedlings by disrupting belowground mutualisms. PLoS Biol. 4:e140. doi: 10.1371/journal.pbio.0040140

Teste, F. P., Kardol, P., Turner, B. L., Wardle, D. A., Zemunik, G., Renton, M., et al. (2017). Plant-soil feedback and the maintenance of diversity in mediterraneanclimate shrublands. Science 355:173. doi: 10.1126/science.aai8291

Veresoglou, S., and Rillig, M. (2014). Do closely related plants host similar arbuscular mycorrhizal fungal communities? A meta-analysis. Plant Soil. 377, 395-406. doi: 10.1007/s11104-013-2008-2

Von Thun, T. (2013). Nutrient exchange through hyphae in intercropping systems affects yields. Natural Sci. Educ. 42:24. doi: 10.4195/nse.2013.0001se

Weremijewicz, J., and Janos, D. P. (2013). Common mycorrhizal networks amplify size inequality in Andropogon gerardii monocultures. New Phytol. 198, 203-213. doi: $10.1111 / \mathrm{nph} .12125$

Weremijewicz, J., Sternberg, L. D. S. L.O., and Janos, D. P. (2016). Common mycorrhizal networks amplify competition by preferential mineral nutrient allocation to large host plants. New Phytol. 212, 461-471. doi: $10.1111 / \mathrm{nph} .14041$

Weremijewicz, J., Sternberg, L. D. S. L.O., and Janos, D. P. (2018). Arbuscular common mycorrhizal networks mediate intra-and interspecific interactions of two prairie grasses. Mycorrhiza 28, 71-83. doi: 10.1007/s00572-0170801-0

Whitehead, D. C., Dibb, H., and Hartley, R. D. (1981). Extractant ph and the release of phenolic compounds from soils, plant roots and leaf litter. Soil Biol. Biochem. 13, 343-348. doi: 10.1016/0038-0717(81)90074-2

Wilson, G. W. T., Hartnett, D. C., and Rice, C. W. (2006). Mycorrhizalmediated phosphorus transfer between tallgrass prairie plants Sorghastrum nutans and Artemisia ludoviciana. Funct. Ecol. 20, 427-435. doi: 10.1111/j.1365-2435.2006.01134.x
Yang, Q., Li, B., and Siemann, E. (2015). Positive and negative biotic interactions and invasive Triadica sebifera tolerance to salinity: a crosscontinent comparative study. Oikos 124, 216-224. doi: 10.1111/oik.01552

Yang, R. Y., Zhou, G., Zan, S. T., Guo, F. Y., Su, N. N., and Li, J. (2014). Arbuscular mycorrhizal fungi facilitate the invasion of Solidago canadensis L. in southeastern China. Acta Oecol. 61, 71-77. doi: 10.1016/j.actao.2014. 10.008

Zabinski, C. A., Quinn, L., and Callaway, R. M. (2002). Phosphorus uptake, not carbon transfer, explains arbuscular mycorrhizal enhancement of Centaurea maculosa in the presence of native grassland species. Funct. Ecol. 16, 758-765. doi: 10.1046/j.1365-2435.2002.00676.x

Zhang, F. J., Li, Q., Chen, F. X., Xu, H. Y., Inderjit, and Wan, F. H. (2017). Arbuscular mycorrhizal fungi facilitate growth and competitive ability of an exotic species Flaveria bidentis. Soil Biol. Biochem. 115, 275-284. doi: 10.1016/j.soilbio.2017.08.019

Zhang, F. J., Li, Q., Ellen, H. Y., Chen, X., and Wan, F. H. (2018). AM fungi facilitate the competitive growth of two invasive plant species, Ambrosia artemisiifolia and Bidens pilosa. Mycorrhiza 28, 703-715. doi: 10.1007/s00572-018-0866-4

Zhang, Y. M., Wang, Y., Li, Q., Zhang, F. J., and Wan, F. H. (2015b). Mechanism of AM fungi on competitive growth between invasive plant Flaveria bidentis and native plant Setaria viridis. Acta Bot Boreal-Occident Sin. 35, 1215-1221. doi: 10.7606/j.issn.1000-4025.2015.06.1215

Zhang, Y. M., Zhuang, W. W., and Downing, A. (2015a). The influence of biological soil crusts on N-15 translocation in soil and vascular plant in a temperate desert of northwestern China. J. Plant Ecol. 8, 420-428. doi: $10.1093 /$ jpe/rtu033

Conflict of Interest: The authors declare that the research was conducted in the absence of any commercial or financial relationships that could be construed as a potential conflict of interest.

Copyright (c) 2021 Chen, Li, Wang, Meng, Jiao, Yin, Xu and Zhang. This is an open-access article distributed under the terms of the Creative Commons Attribution License (CC BY). The use, distribution or reproduction in other forums is permitted, provided the original author(s) and the copyright owner(s) are credited and that the original publication in this journal is cited, in accordance with accepted academic practice. No use, distribution or reproduction is permitted which does not comply with these terms. 